\title{
Change and Dilemma of School Feature Development of Three Junior High Schools in the Remote and Rural Areas of Taiwan
}

\author{
Shan-Hua Chen \\ Associate Professor, Graduate Institute of Educational Administration and Policy Development \\ National Chiayi University, Taiwan \\ E-mail: shanhua@mail.ncyu.edu.tw \\ Hsuan-Fu Ho \\ Associate Professor, Graduate Institute of Educational Administration and Policy Development \\ National Chiayi University, Taiwan \\ E-mail: hfho@mail.ncyu.edu.tw \\ Cheng-Cheng Yang (Corresponding Author) \\ Assistant Professor, Graduate Institute of Educational Administration and Policy Development \\ National Chiayi University, Taiwan \\ Tel: 886-5226-3411Ｅ-mail: yccjason@gmail.com
}

Received: January 19, 2012 Accepted: January 31, 2012 Online Published: April 20, 2012

doi:10.5539/ies.v5n3p49 URL: http://dx.doi.org/10.5539/ies.v5n3p49

\begin{abstract}
This research is based on qualitative approach and applies in-depth interview with three principals and administrators in three junior high schools located in the remote and rural areas of Taiwan. The aim of this paper was to explore the school feature development process in these three schools. The findings of this study were as follows: most of students' parents in these three remote and rural schools are labors and have relatively lower social and economic status in the Taiwanese society. School education becomes an important way for these students to develop their academic, cultural, and technical competences. Second, most of the students' learning motivation and academic performance were not well, but good at athletics or vocational skill. Besides, most of the features created by the schools would not last due to the un-stabilization and away of teachers, short of financial support, and lack of favor from community. Fourth, an important reason of developing school features of these three schools is out of the competition between the urban schools. The decline of the birth rate in the whole society of Taiwan also facilitates the motivation. Fifth, parents of these three schools do not support students' participation in local cultural or local career related curriculum. Parents would have a high expectation on school education's effects on their children's future competitiveness.
\end{abstract}

Keywords: Remote and rural area schooling, School feature development, School-community relationship

\section{Introduction}

The aim of school education is to transfer and preserve knowledge. School education also has the function of transmitting educational values and cultural heritage. School culture is constructed by organizational members inside the school; these members include teacher, staff, student, parents, and community. Each school will also be influenced by its social and geographic contexts. The interactions between human resource, financial support, and community will form unique characteristics of one school. These characteristics are formed by organizational members, social and geographic context, and school-community relationship. The combination of these characteristics is so-called school feature.

School features include school building, school facilities, teacher-student relationship, teacher quality, organizational 
structure, school leadership, school culture, student achievement, parent involvement, etc. These features can be observed from every perspective within the school.

Globalization has foster economic and cultural connection between nations in the world. One of the main effects of globalization is the assimilation of education systems among different countries (Mok, 2003). In this context, how to promote and preserve school features and create a diverse school environment for students is a critical issue internationally.

The main purposes of this study are three folds. First of all, this study is going to understand the formation of school features of three schools located in the remote and rural areas of Taiwan. The second purpose is to explore the development of school features of these three schools. The third purpose is to analyze the motivations of educational changes in these three schools. Recommendations of future research are elaborated in the last section of this study.

\section{Literature Review}

The literature reviews of this study include two main sections. First of them is to review the rise of curriculum specialization. The second section is to discuss the debates of curriculum specialization in different countries.

\subsection{The Rise of Curriculum Specialization}

The implementation of parental choice is often advocated for the increased flexibility that they offer. The advocates assert that child is not the creature of the general public or the nation, and thus, those who nurture him/her should have the right and the duty to select the best way to prepare their child to live up to their potentials. In order to improve the parental choice equity, an expansion of the choices of the types and themes of the curriculum is necessary. Greater choice allows parents to decide upon the type of school they prefer and on which particular curriculum best suits their children's educational needs (Adnett and Davies, 2000).

There are also incentives for schools to spontaneously differentiate themselves from other schools. The marketization of education, coupled with the aforementioned parental choice thrust in many countries, has encouraged competitions among schools. In order to gain a niche in the fiercely competing educational market, it is necessary to differentiate school product from the competitors (Patterson, 2001; Jones, 2010). In order to better response to parental preferences, many schools have created some distinguished curricula, hoping that these distinguished curricula will result in an overall increase in application for enrolment (Davies, Annett, and Turnbull, 2003). However, not all schools under the marketization pressure would initiate a new curriculum. Adnett and Davies (2000) suggest that market-based reform might initially increase curriculum conformity rather than diversity, while overtime there are likely to be greater impetus for schools to differentiate and diversify, and this is especially true for schools who are least able to resource them.

Finally, many governments in the world encourage diversity and differentiation of education. The U.S. Government, for example, has conducted many school reforms to facilitate this goal, such as school within a school, magnet and thematic schools, open enrollment within and across school districts, and charter schools, etc. (Godwin, Kemerer, Martinez, and Ruderman, 1998). England, for another example, the emergence of specialist schools is not a market-driven phenomena, rather, it is clearly powerfully state-driven (Gorard and Taylor, 2001; Riley, Maden, and Murphy, 2003). Singapore is no exception, the Singapore government has been encouraging schools to identify and develop niche of excellence to enable schools to nurture the unique talents of their students (Goh, 2006). Since most specialist schools in these countries may get an extra grants from the government, money become an important impetus for schools to differentiate their curriculum (Higham, Sharp, and Priestley, 2000).

\subsection{Debates of Curriculum Specialization}

Although schools are encouraged to develop their distinguished curriculum building on their particular strengths, most of them "create" their specialized curriculum merely through reinvention of the traditional curriculum or imitating other's academic innovations. Moreover, governments often see the specialist program more as a general school improvement initiative but not an innovation of curriculum design (Smithers and Robinson, 2009).

Although some specialist schools in England did attract greater numbers of pupils from relatively advantaged home backgrounds (Higham, Sharp, and Priestley, 2000), there is little support for the assumption that parents desire a distinctive curriculum. Since most parents have a stronger preference for academic achievement, rather than personal development or social schooling output, they often worry about whether strength towards one curriculum area is at the expense of performance in other subjects(Davies, Adnett, and Turnbull, 2003; Adnett and Davies, 2000). Another question arises as to whose demand is being met in the market and whether the demand is rational. The demand from the immediate consumer is shaped by their motivation, which may or may not be knowledge-based. In other words, it is difficult to assure that their demands are more rational or truly fit to their needs (Lee, 1991). 
Some further argue that the decisions toward what distinctive curriculum is to be developed are often based mainly on the principal's or school heads' preferences, rather than consensus of school members or wishes of consumers (Webb and Vulliamy, 1999). Some governments even encourage schools to build their niche of excellence in the area of sports or arts without providing adequate guides or training required for niche selection. Goh (2006) takes Basketball as an example, and he claims that basketball is often selected to be the distinctive curriculum, but does basketball reflect the needs of the consumers? Whether basketball can attract more students? Does basketball provides parents and students with better marketable skills are still open questions.

Internal resistance is another major obstacle for school curriculum reforms. Successful implementation of the specialist curriculum requires teachers to receive necessary training and professional development so that they will have the ability to accomplish their instructional goals, which cost a great deal of time, energy, and money (Peebles, 2004). Furthermore, the sunk costs in human capital have inhibited schools to develop their own distinctive curriculum. Since most teachers have already invested a great deal of time in preparing the traditional or conventional curriculum, it is very difficult for them to give up what they have already acquired in pursuing of a brand new curriculum that may cost them extra investments (Davies and Adnett, 2003).

The establishment of specialist schools not only requires these specialist schools to result in a higher student achievement, but more importantly, to share their expertise with other schools and provide benefits to the local community. Although most specialist schools on average successfully add more value to students than their non-specialist counterparts, they failed to share their expertise with other schools (Levačić and Jenkins, 2006). Adnett and Davies (2003) further alert that most of the specialist school programs reward schools inappropriately, which merely encourage competition but discourage mutually beneficial cooperation between schools.

\section{Research Method}

\subsection{Selection of Research Fields}

Three junior high schools in the remote and rural areas of Taiwan were selected. These junior high schools are those recognized as priority-zone schools by the Ministry of Education in Taiwan. The priority-zone school means the school is located in remote and rural areas of Taiwan and students enrolled in these schools are economically and culturally disadvantaged. The researchers contact these schools and received permission of conducting in-depth interview and observation in these schools.

\subsection{The Contextual Background of Three Selected Schools}

In this section, we will introduce the context background of these three schools. The information will include geographic environment, surrounding natural resource, economic activity, and students' family background.

\subsubsection{Junior High School A}

Some parents in school A are farmers, they own land property and plant tea and fruits as their main economic activity. Most parents in school A are temporary workers who help farmer's planting activities, their economic condition is not stabilized. Therefore, students in school A sometimes will not able to pay their tuition or lunch fee on time. School A will help their students apply supplemental funding from the Taiwan government. The student enrollment region of school A is very wide; most students need their parents to pick them up after schooling. There are nine classes and about three hundred students in this school. The current challenge of school A is the enrollment competition from schools in the urban areas. Upper and middle class family will choose urban schools instead of school A because of the unbalanced education resources.

\subsubsection{Junior High School B}

School B's location is close with a reservoir and has profound natural resource. It costs about one and half hour drive from urban city to this school and there are only two buses available in this region. The transportation condition is not good. Most parents of this school are farmers and their social and economic status is not high. This school has high ratio of disadvantaged students, such as aboriginal students and low social economic status. Because of school B's remote location, students' tuition and lunch fee can be fully funded by the Taiwan government. Their current challenge is the same as school A, that upper and middle class family in this region will choose urban schools because of the unbalanced educational resources and cultural capital.

\subsubsection{Junior High School C}

School C is located in the southwestern area of Taiwan. School building is traditional style and most of the posts in the student hall are about student achievement. This reveals that this school emphasizes students' academic performance. Most parents of this school are fishers and their social economic status is not high. The decreasing of student enrollment is the current crisis of school C. The decrease of student number is partly because of the decline 
of birth rate in Taiwan and another reason is the tight competition between another regional junior high school.

\subsection{Research Design and Implementation}

This research is based on qualitative approach, we apply in-depth interview as research method to explore administrator and teacher's thinking on school management and school feature construction. The procedure of in-depth interview contains three main steps. First of all, we construct the main themes of this research. Second, we list interview questions based on the themes and literature review. Thirdly, when we conduct in-depth interview with administrators and teachers, we adjust our questions based on contents and interviewee's feedbacks.

The time of each on-site visit is one day. Because every administrator is busy and they only have limited free time when in school, we will interview the principal firstly when we arrive the school. After the interview with principal, we would then interview other administrators and teachers. The main focus of our interview questions is about how administrator's different position would reflect their thinking about school feature construction and management. The second focus is about resource control, resource usage, and resource source.

Each interview would be recorded as an electronic file and be stored in the computer. We would transcript every interview and code it. The coding of our interview is based on the following format: school code-interview date-interviewee. For example, school A-06Jan04-principal means we interview school A's principal on Jan. 04, 2006.

\section{Research Result}

\subsection{The Construction of School Feature in the Remote and Rural Area}

Three schools all have their own specific and unique natural resource and geographic location. Therefore, three schools all try to combine their school feature with their local contexts. All three schools try to develop their school-based curriculum based on local community and local context. For example, the local community of school A surrounds by historic spots. Thus they combine their curriculum of social science with these spots. Some parents are farmers, their farms and economic activities are included into their school-based curriculum.

"Our local teaching is to visit farms, such as persimmon farm, to introduce the production of persimmon cookie. Though students are interested in these activities, some students would say they know these farms well because that's their families' lives." (School A-06Jan12-director of instruction office)

Second, the geographic location of school $\mathrm{c}$ is close with the beach and ocean, thus there are a few temples surround the school. In the context of Chinese culture, fisher village will pray to the Buddha of sea and pray for safety and peace. School $\mathrm{c}$ tries to connect the local culture of fisher village with school feature; they include the local activity and culture of temple and fisher village into their school-based curriculum.

"The local environment and community of our school is a fisher village, our parents generally think being a fisher is not a good job when considering its earning and economic returns. Parents do not wish their children to become a fisher, therefore, when we include some technical curriculums into our school education, it becomes very popular. These technical curriculums include beauty industry, hair cut and design, computer and electronic basic skills." (School c-06Jan09-pricipal)

Third, the local community of school B develops their local economic activity on farming. Their economic activity especially focuses on bamboo industry, thus bamboo relating products become the local specialty. That is the reason why school B would corporate with local elders and experts to include local products into their school-based arts and humanity curriculum. But, it is still challenging to integrate local activity and culture with school feature construction. Parents and school experts are not teachers, though they are willing to teach local cultures to the students, they cannot adjust themselves as a teacher.

"Though it is really good to include local culture into our school-based feature creation, but when we invite parents or local experts to teach, for example, bamboo arts, they feel it is very difficult to be a good teacher" (school b-06Jan04-director of student affairs)

Based on our interview results and observation of these three schools, the challenges of building school features include two main difficulties. First of all, teachers are not fully rooted into the local culture. Second, parents and local experts cannot support teaching very much.

\subsection{School Feature Types and Development of Three Remote and Rural Schools}

In the above section, we discuss three schools' trial on integrating local culture and geographic environment into their school feature. In this section, we are going to discuss these three school's trial on another perspective of building school feature. This approach is to make good use of teachers' expertise and students' interests as their 
school feature construction.

First of all, school A builds its feature on baseball team and technical education. In terms of their baseball team, they will recruit students who are talented in baseball and provide them dormitory and funding support. When students have good performance on baseball, these students can be recruited by other senior high school baseball teams when they graduate.

"Some of our baseball team graduates are baseball players of our national team, some of them also enter college and universities because their expertise in baseball. This is the reason why we keep baseball team as one of our school features." (School A-06Jan12-director of counseling office)

Another school feature of school A is their technical education. School A has a specialized technical education building. Because of technical education, many parents recognize school A's effort in teaching students.

"Our technical education includes computer and electronic basic skills, cooking, and facility maintenance. If students choose not to continue their senior high school attendance, they can enroll into our technical education programs, some of our students get national license of techniques which are very helpful of future employment" (school A-06Jan12-director of counseling office)

The student population of school B includes a relatively higher percentage of indigenous students. Many indigenous students in school B interested in sports and music, so school B is working hard on physical education and musical education and trying to set up these two curriculum as their school features.

Since school B is located in a remote and rural area, the funding source becomes their main obstacle of building physical education and musical education as their own school features.

"Most of our funding is paying teachers to teach sports and music, we only have very few funding left for the equipment and musical instrument's maintenance, this is our main difficulty" (school B-06Jan19-director of student affairs)

Another challenge of school B is their geographic location, since it is very far away from the nearest city, it is difficult for them to run technical education because teachers who expertise in techniques have to commute from urban city for a long time. Limited time for teaching and limited resources are the barriers of building technical education as their school feature.

School C's story is a little bit different from the above two schools. Long time ago, school C once has a handball team and this team is one of their most famous school features. But, when the handball team coach retires, they lost this school feature. Thus we can see the importance of human resource and teacher's expertise on the formation of school feature. After that, school $\mathrm{C}$ is trying hard to develop some other school features, such as Tae Kwon Do, music, and Chinese martial arts. But when the coach or specialized teacher moves to another school, then that feature disappears.

School $\mathrm{C}$ has no choice but to apply supplemental funding from the Ministry of Education in Taiwan and luckily they received the funding and starting to develop their own technical education and cooperate with nearby technical senior high schools, so their school feature becomes technical education which include computer basic skill, beauty management, hair cut, and electronic skills. As director of academic affairs said:

"We would conduct a school-wide survey when students are in their third year in this school, if students are willing to participate in this technical education program, then we will have them do the aptitude test and help them decide which kind of technical education they are interested in" (school c-07Jan11-director of academic affairs)

Comparing the process of school feature development of these three schools, they all tried to combine and integrate school curriculum with their local environment, culture, activities, and community members, however, three schools all respond that it's very challenging to do so. Since these three schools are all in the remote and rural areas of Taiwan, parents would have high expectation on school education's effects on their children's future competitiveness in the job market, employment, and earning. That is the reason why technical education becomes an easier way of school feature construction and is more popular among students' parents.

\section{Conclusion}

This research is based on qualitative approach and applies in-depth interview with three principals and administrators in three junior high schools located in the remote and rural areas of Taiwan. Through the analysis of this research, we know that most of students in these three remote and rural schools, their parents are labors and have relatively lower social and economic status in the Taiwanese society. When parents cannot offer very much economic and cultural capital for their children, school education becomes an important way for these students to develop their academic, cultural, and technical competences. And this is also the reason why these three junior high 
schools are actively developing their school features and school-based curriculums.

Another important reason of developing school features of these three schools is out of the competition from the urban schools. The decline of the birth rate in the whole society of Taiwan also facilitates the motivation of these three schools to build their features.

Although all these three schools have a long history, their location of remote and rural areas still hinders their attraction for new students. These three schools all try to integrate community resources, such as local activities, culture, technical experts, but it is still difficult because of the scarcity of funding and experts who have both teaching ability and local cultural competence.

Also, parents of these three schools do not support students' participation in local cultural or local career related curriculum. We try to explore the reason and we think there maybe an indirect relationship existing between parents' expectation on school education and their reaction to these school features. Parents would have a high expectation on school education's effects on their children's future competitiveness in the job market, employment, and earning.

Though technical education becomes a possible way of these three junior high schools to develop their school features, but most of them are not or limitedly supported by the government. Thus the policy implication of this study is to rethink the effects of funding on the school education of remote and rural areas.

\section{Limitation and Recommendations}

This research is based on qualitative approach and applies in-depth interview with principals and teachings of three remote and rural area schools in Taiwan. Since the sample of this study is limited and the essence of a qualitative research is not to refer the findings to all cases, thus the limitation of this study is the results and findings can only explain the school feature building process in the similar context and community environment of Taiwan.

Some future research implications are generated via the findings of this research. What are parents' expectations on school education in the remote and rural areas? Why technical education becomes a popular school feature in these areas? Does the popularity of technical education reflect parents' desire of social mobility or their disappointment of school education? All these questions are worthy of further investigation. Also does the school feature building process reflect different countries' education system, social values, and cultural heritage? This research question can be answered by conducting research in different countries in the world.

\section{References}

Adnett, N., \& Davies, P. (2000). Competition and curriculum diversity in local schooling markets: theory and evidence. Journal of Educational Policy, 15(2), 157-167. http://dx.doi.org/10.1080/026809300285872

Adnett, N., \& Davies, P. (2003). Schooling reforms in England: From quasi-markets to co-opetition? Journal of Education Polic, 18(4), 393-406. http://dx.doi.org/10.1080/0268093032000106848

Davies, P., Adnett, N., \& Turnbull, A. (2003). Market forces and diversity: Some evidence from the 14-19 curriculum. Journal of Curriculum Studies, 35(4), 479-498. http://dx.doi.org/10.1080/00220270305519

Godwin, K., Kermerer, F., Martinez, V., \& Ruderman, R. (1998). Liberal equity in education: A comparison of choice options. Social Science Quaterly, 79(3), 502-522.

Goh, J. W. P. (2006). To niche or not to niche?- A caveat on the development of niche areas in Singapore schools. Policy In Education, 34(3), 51-62.

Gorard, S., \& Taylor, C. (2001). The compostion of specialist schools in England: Track record and future prospect. School Leadership and Management, 21(4), 365-381. http://dx.doi.org/10.1080/13632430120108916

Higham, J., Sharp, P., \& Priestley, M. (2000). Developing diversity through specialization in secondary education:

Comparing approaches in New Zealand and England. Compare, 30(2), 145-162. http://dx.doi.org/10.1080/713657461

Jones, D. L. (2010). Developing a convention and event management curriculum in Asia: Using blue ocean strategy and co-creation with industry. Journal of Convention and Event Tourism, 11(2), 154-158. http://dx.doi.org/10.1080/15470148.2010.485260

Lee, R. (1991). Modularisation and the curriculum: Flexibility and empowerment in teaching and learning. Journal of Geography in Higher Education, 15(2), 205-210. http://dx.doi.org/10.1080/03098269108709152

Levačić, R., \& Jenkins, A. (2006).Evaluating the effectiveness of specialist schools in England. School Effectiveness and School Improvement, 17(3), 229-254. http://dx.doi.org/10.1080/09243450600697267 
Mok, K. H. (2003). Similar trends, diverse agendas: Higher education reforms in East Asia. Globalization, Societies, and Education. 1(2), 201-221. http://dx.doi.org/10.1080/14767720303910

Patterson, J. C. (2001). The truth about school choice. Curriculum Administrator. 37(1), 38-42.

Peebles, L. D. (2004). Curriculum issues and charter schools: The case of Marblehead Charter School. Curriculum and Teaching Dialogue, 6(1), 1-11.

Riley, K., Maden, M., \& Murphy J. (2003). Big change question: Has choice, diversity and marketization improved the quality and efficiency of education? Journal of Educational Change, 4(1), 63-80. http://dx.doi.org/10.1023/A:1023047918260

Smithers, A., \& Robinson, P. (2009). Specialist school success is based on an illusion. Education Journal, 115, 38-39.

Webb, R., \& Vulliamy, G. (1999). Managing curriculum policy changes: A comparative analysis of primary schools in England and Finland. Journal of Educational Policy, 14(2), 117-137. http://dx.doi.org/10.1080/026809399286404 